
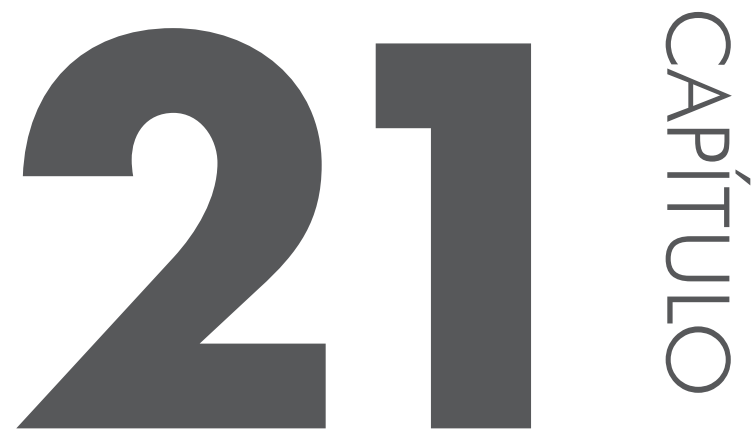

\title{
Estudantes africanos, interculturalidade e os (des)encantos da vinda e da vida no Brasil
}

\section{Juliana Okawati}

Mestre pelo Programa de Pós-Graduação em Antropologia Social/UFSC

Em um cenário de experiências extras locais, desde a década de 1960, nos deparamos com uma dinâmica particular, em que jovens estudantes africanos chegam ao Brasil determinados a cursar carreiras profissionalizantes nas instituições de ensino superior desse país pelo PEC-G (Programa de Estudantes-Convênio de Graduação). ${ }^{119}$ Esse tipo de deslocamento pode ser entendido como uma mobilidade específica, haja vista a política internacional do governo brasileiro que incentiva e autoriza esses estudantes a permanecerem no Brasil durante uma temporada de estudos.

Por meio desse programa, e tendo em vista a crescente demanda de formação acadêmica no exterior, podemos dizer que estamos a diminuir as distâncias físicas e a intensificar a comunicação entre os povos. Assim, através da convivência respeitosa e do diálogo, os diferentes grupos podem interagir de forma horizontal e sinérgica, desvendando os encantos que cada cultura pode revelar: "a hibridação como processo de intersecção e transações é o que torna possível que a multiculturalidade evite o que tem de segregação e se converta em interculturalidade" (CANCLINI, 2001, p. 26).

119 Além de África, o programa conta com estudantes provenientes das Américas e Ásia. Centralizamos aqui nas condições daqueles estudantes africanos, que hoje representam a grande maioria no cenário da UFSC. 
Conforme aponta Grimson (2011), ainda que a multiplicidade não exista fora da interação, em distinto grau e intensidade, com diferentes fins e meios, necessitamos aludir especificamente à "interculturalidade". Pois, essa citação faz referência à característica crucial do mundo contemporâneo: a multiplicidade interatua e a interação não anula as diferenças. Como assinala Barth (2003), a diferença se produz na interação, bem como nas intersecções se produzem as apropriações, resignificações, combinações e também resistências, e, desse modo, por meio das reafirmações, se constituem os modos de ser africano no Brasil.

Portanto, tratamos aqui de um processo dinâmico, em que os significados circulam com ações e reações, por vezes inesperadas, das partes, indo desde o fascínio pela diferença imaginada até o estranhamento total e a hostilidade, do encantamento dos estrangeiros com os povos locais até o afastamento e o isolamento diante das rejeições a que estão expostos.

De tal maneira, na medida em que os estudantes africanos conseguem sustentar-se na sociedade que escolheram para viver convivendo com o "outro", também conseguem manter vivas as suas relações com a "terra de origem”, e, nessas condições, possibilitam resguardar aspectos que remetem aos seus respectivos valores, regras, crenças e atitudes de família.

Não deixa de existir, assim, algo de contraditório e ambíguo nessa situação, que possibilita a esses estudantes se desenvolverem em outras terras, recriando um sentimento de reconhecimento próprio e de pertença tão importantes para a identificação desses indivíduos. Como apontado por Gusmão (2008, p. 8), “o que aprendem e o que esquecem ao permanecer longo tempo, fora de lugar, é hoje o desafio para as autoridades dos países de origem”. A autora ressalta que os estudantes se consideram sujeitos modernos, globalizados e portadores de perspectivas, de valores de outra ordem que se contrapõem aos valores e costumes próprios dos contextos mais tradicionais.

Como salienta Hall (1998, p. 97), “os deslocamentos ou os desvios da globalização mostram-se afinal mais variados e mais contraditórios do que sugerem seus protagonistas ou oponentes”. Logo, como explicar que, mesmo com a próspera ampliação dos fluxos migratórios globais e intercâmbios culturais, tem-se intensificado os fundamentalismos? (GRIMSON, 2011). Segundo Grimson (2011), as culturas são mais híbridas que as identificações, isso é, as fronteiras culturais são as fronteiras de significados, e as fronteiras identitárias representam as fronteiras de sentimento e de pertença. De tal modo, as práticas culturais cruzam fronteiras que as identificações reproduzem e reforçam. Além disso, o fato de interagirem com alguns aspectos de uma determinada cultura não implica necessariamente em ter uma identidade em comum.

Desse modo, o grupo de estudantes se sobressai por revelar e assumir para 
si distintas características pré-identificadas aos diferentes subgrupos de pertencimento em seus locais de procedência, que, por sua vez, são compostos pelos mais variados perfis individuais, assumindo seu caráter relacional e situacional. Sobre essa qualidade multisituacional, Hall (2003) destaca que estas formas de identificação estão introduzindo novas negociações identitárias que ora reduzem, ora ampliam os significados, como, por exemplo, ser estudante da UFSC, ser estrangeiro, ser africano, ser negro etc.

Finalmente, a questão da identificação nunca é a afirmação de uma identidade pré-dada, nunca é uma profecia autocumpridora - é sempre a produção de uma imagem de identidade e a transformação do sujeito ao assumir aquela imagem. A demanda da identificação - isto é, ser um para um Outro - implica a representação do sujeito na ordem diferenciadora da alteridade. (BHABHA, 2010, p. 76.)

Sendo assim, ao chegarem ao Brasil, comumente esses jovens são recebidos pelo "outro" a partir de um tratamento homogêneo, portador de identificações genéricas e simplistas, sejam elas primordialmente relacionadas à procedência, à condição de estrangeiro e também à 'raça', enquanto categorias simbólicas e sociais.

A definição exógena recobre todos os processos de etiquetagem e de rotulação pelos quais um grupo se vê atribuir, do exterior, uma identidade étnica. Quando ela trabalha sozinha, define uma situação em que uma identidade é atribuída a coletividades a quem se nega simultaneamente o direito de elas mesmas se definirem (WALLERSTEIN apud POUTIGNAT; STREIFF-FENART, 1998, p. 142).

Pelas vozes apresentadas dos estudantes, e em suas narrativas, percebe-se que conceber as identidades em seus grupos de convivência, no interior das dinâmicas processuais, acaba de certa forma direcionando esses estudantes na incorporação de novas identidades. Isso posto, depara-se aqui com o que denomino de reapropriação identitária desses sujeitos, uma vez que a "identidade africana" prevalece dominante nos discursos exógenos, refletindo na sua própria autoidentificação que incorpora tal "africanidade".

De tal modo, se admite a "comunidade africana" 120 como forma de organização social em que seus membros se identificam e são identificados como tais

120 É importante ressaltar que o uso do termo "comunidade" remete aqui a um forte senso de identidade grupal homogeneizador (HALL, 2003), que passa a existir a partir de sua chegada ao Brasil. Contudo, quando se referencia a esta, não se trata de aplacar suas diferenças culturais e individuais, mas, sim, de expor uma situação compartilhada da vivência na cidade de Florianópolis, e, nesse caso, na UFSC. 
pelos outros, constituindo uma categoria distinta de outras categorias de mesma ordem (BARTH, 1969 apud CARNEIRO DA CUNHA, 2009). Nesse sentido, como apresenta Carneiro da Cunha (2009, p. 239), a construção dessa identidade étnica do grupo remete a tradições ideológicas, "elementos culturais que, sob a aparência de serem idênticos a si mesmos, ocultam o fato essencial que, fora do todo em que foram criados, seu sentido se alterou".

Portanto, se é aqui no Brasil que angolanos, moçambicanos, guineenses, cabo-verdianos, camaronenses etc. passam a ter "África” como meio de encontro de identidades e de interação entre si, é aqui também que se (re)encontram, criando vínculos com seus pares, a partir de diferentes perspectivas, refletindo-se em "Áfricas" contextuais. Assim, ao mesmo tempo que "aparentemente" quebram-se as fronteiras dos Estados-nação, a partir daí, surgem também outras relações de oposição dialética - "Nós e eles" - correspondida por africanos e brasileiros, negros e brancos, estrangeiros e locais etc., instaurada junto à problemática que permeia a ideia da origem comum e da saliência que recobre o conjunto dos processos pelos quais os traços étnicos são realçados na interação social (POUTIGNAT; STREIFF-FENART, 1998).

\section{(Des)encantos da vinda e vida no Brasil}

A “comunidade africana" se sobressai por revelar e assumir para si distintas características pré-identificadas aos diferentes subgrupos de pertencimento em seus locais de procedência, que, por sua vez, são compostos pelos mais variados perfis individuais. No entanto, quando chegam ao Brasil, defrontam-se com imaginários essencialistas sobre o continente africano e os provenientes deste. $\mathrm{O}$ tom da supremacia transparece na visão eurocêntrica da modernidade frequentemente reproduzida pelos brasileiros. Os estudantes africanos relatam como se sentem surpreendidos, e por vezes ofendidos, com questionamentos que recebem: "Como é sair da tribo? Viver na selva?”, "Como você veio pra cá? De barco ou navio?”, "Lá tem carro, estradas?”, "Onde compraram essas roupas? Existem lojas lá?”, “Há escolas em seu país?”, “Onde aprendeu português’? "Você fala errado!” etc.

Apesar do desconforto que o evidente desconhecimento sobre o continente africano produz, alguns dos próprios estudantes tentam justificar tais indagações responsabilizando a mídia sensacionalista, com reportagens que apenas enaltecem a pobreza do continente de forma genérica e estereotipada. Os estudantes contam que, por vezes, são tidos como coitados, sendo notório um sentimento de pesar em relação aos africanos.

Na África contemporânea, independentemente da frágil legitimidade de muitos Estados africanos, das suas subvalorizadas economias formais e dos seus simulacros de autoridade institucional, os seus povos agarraram-se à vida e à esperança, ignorando 
prognósticos negativos e sobrevivendo à margem de instituições, organismos e poderes que procuraram acorrentá-los. Nesse sentido, para além do mero ato de vontade, a desconstrução das imagens negativas do continente faz-se com estudo, desconhecimento e compreensão atentos à sua personalidade histórica, geográfica e cultural específica. (SERRANO; WALDMAN, 2007, p. 35).

Não há dúvidas de que o imaginário sobre a África deva também ser atribuído ao poder da mídia de manipular e confundir a opinião pública; no entanto, precedente a esse problema encontram-se outros fatores históricos. A ignorância sobre todo o continente africano que paira sobre nossas gerações é, sobretudo, fruto da desvalorização histórica de África e do reducionismo relativo a esse continente que desconsidera a diversidade cultural e geográfica resultante de um currículo escolar que até então ignorava toda a colaboração do negro para a formação histórica, econômica, social e política desse país. ${ }^{121}$

O estigma pelo qual a África é vista e imaginada não se restringe à problemática do grupo de estudantes africanos. Segundo sublinham Serrano e Waldman (2007, p. 11) “essa perspectiva associa-se à exclusão de parcela ponderável da população brasileira do pleno exercício dos seus direitos enquanto cidadãos, veredito que recai de forma marcante sobre os nacionais de origem africana, isto é, os afrodescendentes".

Desse modo, ampliando a reflexão, estudantes negros e cotistas vêm sendo igualmente excluídos, tendo sua capacidade intelectual colocada em questão, sendo vítimas da mesma violência que perpassa as instituições de ensino. Portanto, não se trata apenas de questionar a situação do estudante africano, ainda que seja nosso foco, mas de perceber as inter-relações que os ligam e que, eventualmente por meio da convivência e da interculturalidade, possam oferecer subsídios, ampliando nosso conhecimento no sentido de encontrar saídas para o problema em questão.

\section{A língua e o sistema de ensino}

Frente aos imaginários, percebe-se que, por serem provenientes do continente africano, a capacidade intelectual desses estudantes é frequentemente colocada em questão por professores e outros "colegas" de classe, mesmo que aqui outros tipos de preconceitos estejam associados a esse julgamento. Como aponta Gusmão (2014), pelas dificuldades encontradas com a língua e suas particularidades

121 A partir da Lei n ${ }^{\circ} 10.639$, a temática afro-brasileira se tornou obrigatória nos currículos do ensino fundamental e médio. Espera-se que as novas gerações tenham oportunidade de adquirir novos conhecimentos sobre a África, reconhecendo e valorizando nossas heranças africanas. 
expostas em sala de aula, há rejeição por parte de professores e colegas que os veem como pouco capazes.

Em relação a esse primeiro ponto, o contexto linguístico apresenta-se como aspecto importante, uma vez que a língua portuguesa aparece como elemento de agregação, justamente por ser este um grande elo entre brasileiros e estudantes oriundos dos países lusófonos, ${ }^{122}$ mas que nem sempre se apresenta como fator de aproximação.

No caso dos estudantes provenientes de países em que o português não é língua oficial, a situação pode ser ainda mais complicada. O fato de alguns alunos não dominarem inteiramente a língua portuguesa reprime esses alunos em sala de aula, o que dificulta ainda mais o aprendizado. Mas também no caso dos lusofalantes, maioria entre os estudantes da UFSC, deve-se levar em consideração sua variedade linguística.

Sendo o português a língua oficial de grande parte dos países africanos que fazem parte do acordo de cooperação PEC-G, os estudantes são conduzidos à ideia de que esse seria um ponto de identidade comum entre brasileiros e africanos. Contudo, como aponta Thomas (2007, p. 65), "partir de uma suposta identidade existente entre o Brasil, Portugal e os países africanos de língua oficial portuguesa, me parece um equívoco analítico e um perigo político".

Esse equívoco analítico é logo descoberto pelos estudantes africanos no momento em que chegam ao Brasil. As variadas formas de expressão, os sotaques distintos utilizados e os diferentes significados são responsáveis pelos estranhamentos iniciais que, com o tempo de vivência no Brasil, começam a ganhar sentido. O perigo surge a partir do momento em que, ao invés de aceitarmos que a língua portuguesa é diversificada, a classificamos como certa ou errada, melhor ou pior, a partir de um único ponto de vista, ou seja, de acordo com a norma padrão. Ademais, mesmo concebendo a língua portuguesa como marca compartilhada, essa se torna um problema a partir do momento em que não se admite sua heterogeneidade nas formas de expressão. Assim, o desconhecimento e desrespeito com as diferentes formas que a mesma língua pode ter distanciam e, por conseguinte, excluem esses estudantes, mesmo que aqui outros elementos, sobretudo o preconceito racial, possam estar associados.

Essas diferenças, muitas vezes, não são admitidas dentro do meio acadêmico, sendo caracterizadas como inaptidão, incompetência e erro quanto à forma de escrita desses alunos, considerada diferente da norma padrão pelos avaliadores.

122 Dentre aqueles provenientes do continente africano, destaca-se a representação quantitativa dos estudantes de Cabo Verde, Guiné-Bissau e Angola, respectivamente, como maioria no cenário da UFSC. 
Nesse sentido, os estudantes afirmam que "a língua os trai", uma vez que essa deve "adaptar-se" ao ponto de vista de um português brasileiro que, muitas vezes, não consente na sua variação, impondo suas regras e desrespeitando outras normas de linguagem. Ou seja, paradoxalmente essa língua que supostamente os une é a mesma que os separa.

Ainda no que diz respeito ao sistema de ensino, há outros desafios. Ao chegarem às universidades brasileiras, os estudantes passam a conviver com cobranças e pressão para assegurar o desempenho acadêmico, ${ }^{123}$ e também com um constante sentimento de responsabilidade pessoal, tanto para cumprir os anseios do programa como também daqueles que subvencionaram essa experiência de formação, considerando que este é visto como grande empreendimento não apenas pessoal, mas também familiar.

Tais considerações são referendadas por uma série de experiências vivenciadas por esses estudantes em sala de aula, em que a insegurança e a vergonha evidenciam, por vezes, situações de solidão e tormenta ao defrontarem-se com um sistema de ensino completamente distinto, com cobranças de "base", de pré-requisitos de um ensino médio, frequentemente agravadas pela intolerância e inflexibilidade dos próprios professores.

Obviamente, não se trata de generalizações, até mesmo porque entre tantas experiências problemáticas, também constatamos relatos construtivos, em que há reconhecimento e valorização do conhecimento e da presença desses estudantes. O que não podemos ocultar, mascarar ou camuflar são as ações discriminatórias, que não se restringem unicamente aos estudantes africanos e toma outras dimensões, expostas em seguida.

\section{Racismo e xenofobia}

Ao contrário do imaginário de um Brasil miscigenado, todavia predominantemente negro, que vive em harmonia, os estudantes africanos encontram aqui também a barreira da cor. Esse fator contrasta ainda mais com a realidade do sul do Brasil, e também de Florianópolis, em que o preconceito racial é complexo, camuflado e problemático.

123 Diferente do regimento seguido pela maioria dos estudantes da UFSC, os alunos vinculados ao PEC-G estão sujeitos a uma série de normas, entre elas: não podem ter reprovações por FI (frequência insuficiente); há limite quanto ao número de reprovação em disciplinas; exigências em relação ao IAA (índice acadêmico acumulado) para obtenção de certas bolsas de estudos etc. 
A ocupação territorial da região Sul, atendendo aos interesses das elites intelectuais e políticas do país, de implantar um povoamento com populações provenientes de áreas 'desenvolvidas' e, sobretudo, de tornar o país 'racialmente mais branco', propiciou condições favoráveis aos imigrantes. Com isto, enfatizou a reprodução das desigualdades, confirmando as teorias que a norteou. (LEITE, 1996, p. 3).

Nesse sentido, os estudantes comentam sobre a ausência de cordialidade encontrada no dia a dia, expressa nos olhares e modo como são tratados pelos demais, sendo vários os relatos de discriminação e marginalização, e apontam o preconceito racial como desencadeador dessa problemática.

Colaborando com essas impressões expostas pelos estudantes em questão, numa pesquisa feita com estudantes cabo-verdianos que vivem no Rio de Janeiro, Massat (2002, p. 281) salienta a afirmação do status de estrangeiro em sobreposição ao de negro brasileiro. Dessa forma, para eles, é importante falar com sotaque e realçar essas diferenças: "assim as pessoas sabem que ele é estrangeiro, e não favelado, e o tratam de outra forma. Pelo fato de serem escuros eles são qualificados de africanos. O africano, segundo eles, é um estrangeiro mais bem definido, é um estrangeiro preto". Em consonância com essa condição, Mourão (2014, p. 80), em pesquisa na mesma cidade, verifica:

ao serem confundidos com negros brasileiros, sofrem o racismo duplamente: racial e de classe, sendo a discriminação atenuada apenas quando são identificados como "negros estrangeiros", nomeadamente no ambiente universitário, embora isso não elimine situações discriminatórias também por xenofobia, tanto na universidade como na rua, sendo, em geral, somente valorizados como africanos pelos movimentos negro e antirracista.

Reforçando esta situação, há 15 anos a pesquisa da angolana Verônica Pedro (2000) na UFSC apontava um cenário semelhante, na cidade de Florianópolis:

os estudantes africanos são, por um lado, aceitos pela população por serem considerados intelectuais universitários, munidos de uma condição financeira estável e estrangeiros (Os estrangeiros são geralmente bem vistos); e, por outro lado, são expostos a toda discriminação racial e social, quando confundidos aos afro-brasileiros. (PEDRO, 2000, p. 15, grifo nosso).

No entanto, tal situação narrada atualmente se mescla com outro contexto presente tanto no Brasil como na cidade de Florianópolis. Apontamos aqui duas mudanças significativas que atuam nessa discussão: em primeiro lugar, em virtude da política de cotas, os africanos deixaram de ser praticamente os únicos negros dentro UFSC. Desde 2009, tanto estudantes de escolas públicas, negros e indí- 
genas ingressaram nessa instituição através do Programa de Ações Afirmativas (PAA), efetivando mudanças no panorama atual dessa universidade. O segundo ponto refere-se ao crescente fluxo de imigrações haitianas, ${ }^{124}$ aqui não tratando do contexto acadêmico, e sim de mão de obra que migra em busca de oportunidades econômicas, que, mesmo em condição distinta, passa a refletir na forma com que a sociedade local acolhe os estrangeiros.

Considerando, portanto, ambas as circunstâncias que fazem parte do contexto atual da cidade de Florianópolis, coloca-se em xeque as categorias de negro e estrangeiro, ainda que uma se sobreponha à outra. Mesmo que em um primeiro momento os estudantes concordem que a identificação africana possa ser "melhor vista" em comparação com a de um negro brasileiro, quando descobre-se que este não é possuidor de uma riqueza, que não está aqui com o propósito turístico ou de negócios, e além disso é beneficiado pelos programas de financiamento brasileiro, nesses casos, a situação muda de figura. O preconceito ocorre em todas as esferas, e a experiência em Florianópolis revela quão problemática é estar nessas categorias concomitantemente.

$\mathrm{Na}$ problemática aqui apresentada, não se trata de definir uma categoria como "melhor" ou "pior", mas de perceber diferentes posições que refletem a urgência de medidas ao combate às diferentes formas de preconceito, especialmente no que se refere à responsabilidade institucional.

\section{Encantos e encontros com África}

$\mathrm{Na}$ "terra do outro", esses estudantes procuram recriar à sua volta elementos do seu contexto sociocultural, em grande parte por meio da ressocialização de pessoas em condições similares. Como estudantes do PEC-G, eles chegam sozinhos a um novo país, uma nova experiência de vida, uma nova cidade, por vezes sem conhecer ninguém, normalmente recorrendo aos conterrâneos em um primeiro contato. Aproximam-se por meio das redes sociais, mediante contato de conhecidos e da própria instituição, o que comumente acaba resultando no estabelecimento de vínculos de amizade, e também de moradia. Desse modo, os estudantes conseguem manter relações estreitas com o grupo de mesma proveniência; não obstante, juntos compartilham de uma memória afetiva em relação aos lugares que deixaram para trás, familiares, amigos etc.

Uma vez unidos, mesmo que em subgrupos, esses passam a ser reconhecidos e identificados pela comunidade local e acadêmica, o que também contribui para

124 Ainda que geograficamente distante do continente africano, os haitianos frequentemente recebem um tratamento homogeneizador, são tidos por africanos, o que ocorre também de maneira reversa. 
as categorizações exógenas já mencionadas. Mediante esse contato, considerando todo o imaginário brasileiro, curiosidade e também dúvidas sobre a África, esses estudantes passam a ser questionados sobre o continente. Tendo em vista responder a "demanda" imposta, esses estudantes organizam e participam de encontros, festas e outras atividades sociais em que o tema África é destacado e valorizado, ainda que muitas vezes como cultura exótica. Conforme frisa Carneiro da Cunha (2009, p. 238), "a escolha dos tipos de traços culturais que irão garantir a distinção do grupo enquanto tal depende dos outros grupos em presença e da sociedade em que se acham inseridos, já que os sinais diacríticos devem se opor, por definição, a outros de mesmo tipo".

Nessa perspectiva, participam de uma série de eventos culturais, onde eles têm que fazer atuações que estão voltadas para a demonstração pública das culturas de seus países, nos termos dos diacríticos, o que também acaba contribuindo para uma reaproximação destes com os laços que os ligam à sociedade de procedência. Por outro lado, eles mesmos propiciam a troca de experiências, possibilitando conhecer outros contextos culturais e interagindo entre eles e com a população local.

Dando sequência à organização de eventos relacionados ao continente africano, na UFSC, já se tornou habitual que todo dia 25 de maio os estudantes africanos se organizem para comemorar o "Dia de África”. Geralmente, são promovidos seminários para tratar de temáticas concernentes ao continente, como, por exemplo: lutas dos povos africanos pela liberdade; caso 25 de maio: dia das nações africanas, entre outros.

No discurso que reforça a importância da união dos povos e nações africanas, como é constantemente apresentado nos eventos, nas apresentações culturais, na convivência cotidiana entre eles, é inegável que atritos ocorram, reproduzindo discursos contraditórios. Por serem estudantes em contextos diversos, é comum que tanto compartilhem como discordem em opiniões sobre o desenvolvimento do continente e outros temas associados em momentos de debate entre estes.

Nesse tipo de evento acadêmico, outras categorias temáticas ainda podem ser diluídas em outros momentos: "Dia de Angola", "independência de Cabo Verde e Moçambique", "aniversário da independência de Guiné-Bissau" etc. Mesmo assim, ainda que outros temas estejam em destaque, é muito comum que a grande temática “África” esteja sempre presente, segundo eles, especialmente pela dificuldade dos brasileiros de desvincular essa visão geral e continental. Aqui, portanto, vemos mais uma vez que as representações exógenas criam pautas para as representações endógenas e as reforçam como forma de representação social, cultural e política. 
Nesse espaço de atividades acadêmicas, científicas e culturais, a participação dos estudantes africanos não se resume apenas a datas comemorativas. De formas diferentes, levam suas experiências e contribuem com diversos núcleos de pesquisas, debates, seminários etc., o que tem respaldado a produção intelectual das instituições de ensino brasileiras em variadas áreas de conhecimento. Nessa perspectiva, também tem contribuído com a realização de ações específicas que valorizam a cultura de povos e populações tradicionais de matriz africana, promovendo uma maior visibilidade da cultura negra a partir de diferentes olhares e novas reflexões.

\section{Considerações finais}

Em um momento em que as viagens se tornam cada vez mais comuns e populares, intensificando o trânsito de pessoas e as possibilidades de formação acadêmica no exterior, verifica-se a oportunidade de outras aprendizagens, ampliando os horizontes, tanto dos que vêm de outros "cantos" como também dos que pertencem à mesma localidade. Assim, procurou-se enfatizar as inter-relações entre esses jovens vindos do continente africano com a sociedade de acolhimento, seja essa universitária, seja também relativa à cidade de Florianópolis, refletindo como estas se estabelecem num meio temporário e conflitante, contribuindo para a compreensão dessa mobilidade estudantil.

Temos visto, nos variados trabalhos produzidos por estudantes do PEC-G, o reconhecimento dessa cooperação brasileira, com agradecimentos de solidariedade e gratidão. No entanto, tratamos de mostrar outra frente, na qual podemos identificar também brasileiros como grandes beneficiados dessa cooperação. São imensas as contribuições que esses estudantes estão deixando para nossas instituições, e, sobretudo para nós mesmos. Incluo-me aqui, uma vez que, a partir dos elos criados com esses estudantes, pude repensar e descobrir outras “Áfricas”, senão aquela da "única história”, na qual o continente africano é visto através de ideias que permeiam um tão imaginário carente de conhecimentos.

De tal modo, esse imaginário tramado historicamente por poderosas histórias globais, tal qual até então o sensacionalismo midiático tem se apoiado, é capaz de disseminar um discurso de vitimização da África e dos africanos, acrescido de uma suposta superioridade ocidental, reproduzido pelos brasileiros. Por conseguinte, há uma tendência em falar da África como se todos que ali vivem fossem um único povo, tivessem os mesmos hábitos, a mesma cultura, enfim, o que acaba repercutindo em informações homogeneizadoras. Isso ocorre ainda que, para além das fragilidades sociais, das savanas e da natureza selvagem predominantemente difundida pela mídia, esteja uma série de aspectos invisibilizados, como a produção intelectual, cultural, artística, científica, bem como expressivos dados econômicos. 
Em contrapartida, cientes de uma realidade plural, tratamos esses estudantes de forma a compartilhar de sua trajetória, considerando que ela toma rumos variados e reconhecendo esses estudantes como produtores de conhecimento, intelectuais que têm expandido nossos horizontes, por vezes tão limitados a uma única experiência. Logo, a capacidade intelectual desses estudantes deve sim ser colocada em questão - não para minimizá-la, como frequentemente ocorre em sala de aula, mas percebendo o quão fértil e produtiva podem ser as presenças desses estudantes e o quanto podem colaborar para um novo olhar dos brasileiros sobre a África.

Mediante a distância, “Áfricas” surgem em contextos diversos, e esses estudantes protagonizam um papel significativo em prol da desmistificação dos conceitos e preconceitos que pairam sobre o continente africano. Nessa perspectiva, eles próprios se colocam como pesquisadores e conhecedores aptos a palestrar sobre seus países, o que nos permite pensar que há diversas vozes africanas ressoando nos eventos científicos e culturais que ocorrem dentro dessa universidade, dialogando entre eles e também com o público local.

Portanto, por mais "encantos" que essas práticas inter-relacionais possam gerar, o desafio está em superar as barreiras dos "desencantos" que permeiam a vivência desses estudantes, reforçando e valorizando sua importância como agente cultural capaz de suscitar verdadeiras mudanças.

Em conformidade com essa proposta, o papel da política institucional de acolhimento é essencial, preparando tanto professores como a comunidade local para lidar com a diversidade, tendo em vista que essa discussão não se restringe aos "muros" da universidade; ao contrário, ela perpassa fronteiras que merecem continuar chamando a atenção de pesquisadores e das próprias instituições que recebem esses estudantes.

Ao contrário do imaginário de um Brasil miscigenado que vive em harmonia, os estudantes africanos encontram no Brasil um racismo "estrutural e institucionalizado" gerador de violência, frequentemente naturalizado pela população brasileira, ademais, sobreposto à xenofobia.

Em consonância com essa finalidade, percebe-se a importância da participação desses estudantes africanos, dando voz e destaque contra os abusos cometidos nessas diferentes esferas sociais. Portanto, se é aqui que muitos africanos descobrem a discriminação, é aqui também que podem criar novos espaços e mecanismos para combatê-la. Mediante essa interculturalidade, seja em sala de aula, no cotidiano, na arte, na música, no esporte, na política e em outras esferas, o diálogo entre estes contribui para reflexão a respeito da atual situação dos africanos em Florianópolis, no sul do Brasil e mesmo na África, ou no mundo. 


\section{Referências}

ABRANTES, C. S. A.; SOGBOSSI, H. B. Brasil e África em projetos de cooperação: algumas experiências a partir do ensino superior. O público e o privado (UECE), v. 23, p. 1-13, 2014.

BARTH, F. Temáticas permanentes e emergentes na análise da etnicidade. In: VERMEULEN, H.; GOVERS, C. (Org.). Antropologia da etnicidade: para além de groups and boundaries. Lisboa: 2003, p. 19-44.

BHABHA, H. K. O local da cultura. Belo Horizonte: UFMG, 2010.

CANCLINI, N. G. Culturas híbridas: estratégias para entrar e sair da modernidade. 4. ed. São Paulo: Edusp, 2001.

CUNHA, M. C. Cultura com aspas e outros ensaios. São Paulo: Cosac Naify, 2009.

FONSECA, J. D. A tripla perspectiva: a vinda, a permanência e a volta de estudantes angolanos no Brasil. Pro-posições, v. 20, n. 1, 2009. Disponível em: <http//www.scielo. br/pdf/pp/v20n1/v20n1a03>. Acesso em: 26 nov. 2014.

GRIMSON, A. Los limites de la cultura: crítica de las teorías de la identidad. Buenos Aires: Siglo XXI Editores, 2011.

GUSMÃO, N. M. M. 2008. “África e Brasil no mundo acadêmico: diálogos cruzados”. In: Colóquio Internacional Saber e Poder. Campinas.

. Intelectuais negros: migração e formação entre conflitos e tensões. O Público $e$ o Privado (UECE), v. 23, p. 39-54, 2014.

HALL, S. A identidade cultural na pós-modernidade. Rio de Janeiro: DP\&A, 1998.

. Da diáspora: identidades e mediações culturais. Organização de Liv Sovik. Tradução de Adelaine La Guarda Resende. Belo Horizonte: UFMG, 2003.

HANNERZ, U. Fluxos, fronteiras, híbridos: palavras-chave da antropologia transnacional. Mana, v. 3, n. 1, 1997.

LEITE, I, B. Negros no sul do Brasil: invisibilidade e territorialidade. Florianópolis:

Letras Contemporâneas, 1996.

MASSAT, G. Viajantes profissionais e estrangeiros cabo-verdianos no Rio de Janeiro: experiências do "outro". In: MAGGIE, Y.; REZENDE, C. B. Raça como retórica: a construção da diferença. Rio de Janeiro: Civilização Brasileira, 2002.

MOURÃO, D. E. Estudantes cabo-verdianos no Brasil: tensões raciais e "reafricanização”. O Público e o Privado (UECE), v. 23, p. 73-90, 2014. 
PEDRO, V. T. Identidades traduzidas num mundo globalizado: os estudantes africanos em Florianópolis. 2000. 137 f. Dissertação (Mestrado) - Centro de Filosofia e Ciências Humanas, Universidade Federal de Santa Catarina, Santa Catarina, 2000.

POUTIGNAT, P,; STREIFF-FENART, J. Teorias da etnicidade: seguido de grupos étnicos e suas fronteiras de Fredrik Barth. São Paulo: Unesp, 1998.

SERRANO, C.; WALDMAN, M. Memória d'África: a temática africana em sala de aula. 3. ed. São Paulo: Cortez, 2010. 